\title{
Call for Papers: Special Issue of Earth, Planets and Space (EPS) "Earthquake Forecast Testing Experiment for Japan"
}

One of the newly-introduced main activities under the current Japanese "Observation and Research Program for Prediction of Earthquakes and Volcanic Eruptions (2009-2013)" is to construct forecast systems of earthquake occurrence for Japan. Our approach to this construction is as follows:

- First, to develop the Testing Center, a framework that can support to assess the validity of registered earthquake forecast methods

- Second, to conduct comparative testing experiments within this framework multiple times in determining which of the registered forecast models are better for their forecast accuracy

- Third, to aim at the creation and buildup of sophisticated forecast models, based on results obtained from the multiple experiments

For this purpose, the 1st earthquake forecast testing experiment for Japan will be carried out in 2009. This research activity is in collaboration with the global CSEP (Collaboratory for the Study of Earthquake Predictability) project that is modeled after the California RELM (Regional Earthquake Likelihood Models) project. In order to provide a forum for mutual understanding among participants of the 1st experiment, the international symposium "Toward Constructing Earthquake Forecast Systems for Japan" was held on 27 May 2009 at Earthquake Research Institute, University of Tokyo, Japan. In the symposium, we also discussed to explore the possibility to create next-generation testable models.

To give an overview of the experiment, we propose a special issue of Earth, Planets and Space (EPS). The publication will be limited to papers associated with the four points that have been discussed in the symposium:

1) Testing Center

2) Earthquake forecast models

3) Forecast evaluation methods

4) Exploring the possibility to create next-generation testable models

Contributors to the special issue should submit their papers to the EPS editorial office either by post or e-mail (eps@terrapub. co.jp), following the instructions for regular EPS submission. For details, please visit the following webpage:

http://www.terrapub.co.jp/journals/EPS/, and click on "Instruction for Contributors".

The cover letter should mention "For Special Issue: Earthquake Forecast Testing Experiment for Japan". We encourage electronic submissions. After papers are accepted for this special issue, the authors will receive instructions for the final manuscript from the editorial office. The deadline for manuscript submission is 31 March 2010. This special issue will hopefully be published by the end of March 2011.

For more information on this special issue, please contact the corresponding editor (N. Hirata, hirata@eri.u-tokyo.ac.jp); questions on manuscript preparation should be addressed to the EPS editorial office.

Note: EPS accepts manuscripts of original research contributions only; so-called "review papers" will not be accepted. EPS will review all the manuscripts before publication.

Guest Editors: Naoshi Hirata, University of Tokyo, Japan Thomas H. Jordan, University of Southern California, USA Hiroshi Tsuruoka, University of Tokyo, Japan Kazu Z. Nanjo, University of Tokyo, Japan 